\title{
AS ETAPAS DE INSTITUCIONALIZAÇÃO DA MEDIAÇÃO NO BRASIL
}

\author{
Fernanda Braganca ${ }^{1}$ \\ Carla Faria de Souza ${ }^{2}$
}

\section{RESUMO:}

Trata-se de pesquisa científica que pretende fazer a análise da institucionalização da mediação no Brasil através da construção do seu marco legal e da promoção de políticas públicas e iniciativas que visam fomentar a transformação da cultura social pela paz. O objetivo é mostrar que as propostas legislativas ainda que regulem exaustivamente a matéria não são por si só suficientes para dar engrenagem à esta via consensual de solução de conflitos. Daí a importância da construção de parcerias e do impulso dado pelos órgãos públicos, sobretudo pelo Judiciário.

Palavras chaves: Mediação; Métodos consensuais de solução de conflitos; Institucionalização; Judiciário; cultura de paz.

\section{THE STAGES OF INSTITUTIONALIZATION OF MEDIATION IN BRAZIL}

\begin{abstract}
:
It is a scientific research that seeks to analyze the institutionalization of mediation in Brazil through the construction of its legal framework and the promotion of public policies and initiatives aimed at fostering the transformation of social culture for peace. The aim is to show that the legislative proposals, even if they regulate exhaustively the matter, are not in themselves sufficient to give effect to this consensual way of resolving conflicts. Hence the importance of building partnerships and the impetus given by public agencies, especially by the judiciary.
\end{abstract}

Keywords: Mediation; Consensual methods of conflict resolution; Institutionalization; Judiciary; Culture of peace;

\section{INTRODUÇÃO}

Esta pesquisa tem por objetivo examinar a institucionalização da mediação no Brasil a partir do estudo do histórico do seu regramento legal (novo Código de Processo Civil e lei

\footnotetext{
1 Doutoranda em Mediação de Conflitos no Programa de Sociologia e Direito da Universidade Federal Fluminense - UFF. Mestre em Direito pela Universidade Federal do Rio de Janeiro - UFRJ/FND. Bacharel em Direito pela Universidade Federal do Rio de Janeiro - UFRJ/FND. Graduada em Administração de Empresas pela Universidade Cândido Mendes /UCAM. Pesquisadora do Laboratório Fluminense de Estudos Processuais LAFEP. Advogada. Mediadora Extrajudicial.

2 Doutoranda em Sociologia e Direito na Universidade Federal Fluminense. Mestra em Direito pela Universidade Católica de Petropolis - UCP. Especialista em Negociação pelo Harvard Negotiation Institute Harvard Law. Mestra em Psicologia pela Universidade Católica de Petropolis - UCP. Pós graduada pela Escola da Magistratura do Estado do Rio de Janeiro. Especialista em Direito Público pela Universidade Cândido Mendes. Membro da Comissão de Mediação - OAB /Barra-RJ. Professora e pesquisadora de Mediação e Meios Alternativos de Solução de Conflitos. Professora de Direito Civil, Direito Notarial e Registral. Mediadora Extrajudicial. Atualmente é Oficial de Registro Civil e Tabeliã no Estado de Minas Gerais.
} 
13.140/2015) e o avanço de sua implementação enquanto política pública. Por institucionalização entende-se a construção de um arcabouço legal específico sobre a matéria bem como a sua incorporação no seio social. Na medida em que ganha respaldo normativo, consequentemente garante maior segurança jurídica aqueles que buscam a mediação para resolução de seus conflitos. Entretanto, isso por si só não é suficiente. Mesmo com a tendência de crescente adesão a este procedimento consensual, ainda é pequena frente ao número de pessoas que optam por demandas judiciais no país.

A partir de fontes bibliográficas, o artigo desenvolve este tema em duas partes: a primeira direcionada à análise do histórico do marco regulatório da mediação no Brasil e as iniciativas legislativas no âmbito do Executivo, Legislativo e Judiciário; e em seguida examina algumas propostas para fomento da inserção deste método alternativo na cultura da sociedade. A finalidade é mostrar o panorama normativo até desencadear nos dois diplomas centrais sobre o assunto atualmente: o novo código de processo civil e a lei 13.140/2015; e com base nisso proceder a um exame crítico sobre sua efetivação na mentalidade brasileira. Ou seja, entendendo que a extensa previsão normativa não é suficiente para a popularização de um instituto, é preciso averiguar quais medidas estão sendo tomadas para avançar nesse sentido.

\section{Histórico do marco regulatório da Mediação no Brasil}

Os movimentos relacionados à propagação e incentivo à utilização de meios alternativos de solução de conflitos desembarcaram no Brasil já há algum tempo e exerceram grande influencia para a disseminação da mediação, a qual encontra-se atualmente inserida na vida e no cotidiano da sociedade, graças também ao impulso proporcionado pela atuação dos Poderes Executivo, Legislativo e Judiciário.

A proposta de institucionalização desse método de solução consensual de conflitos no Brasil ganhou relevância sobretudo a partir da década de 90, em que imperava uma realidade jurídica que visualizava o Poder Judiciário como o único capacitado para equacionar as disputas sociais. Conforme ressalta Rodrigues Júnior (2006, p. 161), os operadores do Direito se posicionavam contra o uso do procedimento com receio de perder o controle do processo e a clientela, o que caracterizava uma completa falta de informação sobre o ainda recente instituto.

A partir de então, tendo como exemplo o seu expressivo desenvolvimento em outros países $^{3}$, começou no Brasil um movimento pró-mediação que, apesar de pequeno, despertava o interesse dos profissionais que integravam o meio jurídico-acadêmico. O Poder Executivo, a partir da parceria celebrada entre a Secretaria de Reforma do Judiciário, o Programa Nacional para o Desenvolvimento das Nações Unidas e a Agência Brasileira de Cooperação para fortalecer o acesso à Justiça passou a dar especial estímulo aos projetos que buscavam promover o diálogo entre Estado e sociedade civil ${ }^{4}$. Nesse contexto, no ano de 1997, foi criado o Conselho Nacional de Instituições de Mediação e Arbitragem - CONIMA, abrindo

\footnotetext{
${ }^{3}$ Sobre a Mediação nos EUA e na Europa, respectivamente: ver estudo publicado pelo Parlamento europeu: 'Reebooting' the meditation Directive: assessing the limited impact of its implementation and proposing measures to increase the number of mediations in the $E U$, disponível em: <http://www.europarl.europa.eu/RegData/etudes/etudes/join/2014/493042/IPOLJURI_ET(2014)493042_EN.pdf $\geq$. Acesso em: 12 nov. 2015.

${ }^{4}$ Segundo o Flávio Crocce e a Glaucia Falsarella Foley (2013), a proposta é democratizar radicalmente o acesso à Justiça, mitigando a sua clássica associação com acesso ao Judiciário.
} 
espaço para maiores discussões sobre a mediação, e atualmente já conta com quarenta e duas instituições associadas em todo país ${ }^{5}$.

No mesmo sentido, o Legislativo, procurava inserir a conciliação como uma ferramenta do processo civil brasileiro, seja como uma fase na audiência de instrução e julgamento, onde é realizada pelo magistrado; ou ainda alocada dentro da Lei 9.099 de 1995, que regulamentou os juizados especiais cíveis e criminais, podendo inclusive ser conduzida por leigos (NOBRE, 2015, p.262). Explica Eleonora Coelho (2015, p. 106) que

nesta esteira, o próprio Estado passou a incentivar a adoção de outros métodos e procedimentos para a pacificação de conflitos, em um movimento de descentralização, que ocorre tanto dentro como fora da estrutura judicial. No Brasil, a primeira medida de relevância nesse sentido foi a criação dos Juizados Especiais de Pequenas Causas (Lei $\mathrm{n}^{\mathrm{o}}$ 7.244/84), posteriormente substituídos pelos Juizados Especiais Cíveis e Criminais (Lei $n^{\circ}$ 9.099/95) e Federais (Lei $n^{\circ} 10.259 / 01$ ), os quais objetivavam ser um mecanismo mais adequado para solucionar causas de valor reduzido, pois contam com um procedimento simplificado (em que há incentivo à conciliação, privilégio da informalidade, concentração de atos etc.). A criação dos Juizados teve grande aceitação da sociedade, o que já demonstrava o anseio por meios mais ágeis e eficazes para solução de conflitos. Contudo, não tardou para que tais órgãos também ficassem saturados.

Mesmo sem ter sido contemplada com uma legislação específica a mediação começou a se propagar, ainda que de forma modesta. Insatisfeitos, os seus defensores despertaram para exigir um amparo legal apto a gerar um resultado realmente eficaz desse instituto na solução dos litígios. Desta forma, ganhou expressão a necessidade de formulação de propostas legislativas que buscassem regular o seu procedimento de forma minuciosa e exaustiva. Nessa perspectiva, o termo institucionalização adquiriu característica normativa e se afasta da noção puramente sociológica, que estaria ligada, de forma geral, à organização de ideias, concepções, relações intersubjetivas e padrões de comportamento em torno de um interesse ou finalidade socialmente reconhecidos (BARBADO, 2004, p. 206).

A primeira iniciativa reguladora que tentou ordenar a mediação em território nacional foi o Projeto de Lei n. 4.827 de 1998, de autoria da Deputada Zulaie Cobra ${ }^{6}$. Foi previsto então enquanto um procedimento não-obrigatório que poderia ser instaurado no curso do processo judicial, ou até antes do processo, desde que a matéria objeto de acordo admitisse conciliação, reconciliação, transação ou acordo de outra ordem (Idem, p. 207). Em linhas gerais, este projeto não pretendia regular exaustivamente o processo de mediação e tinha como aspecto fundamental a facultatividade e a flexibilidade das formas, podendo a mediação ser utilizada em qualquer fase do processo judicial (Idem, p. 208).

Em 2004, como parte do Pacote Republicano que se seguiu à Emenda Constitucional $\mathrm{n}^{\mathrm{o}} 45$, conhecida como a que projetou a Reforma do Judiciário, o governo apresentou novo projeto de lei modificando o então Código de Processo Civil de 1973. A redação inicial ficou prejudicada com a aprovação do Substitutivo (Emenda n. 1 - CCJ), que foi enviado à Câmara e à Comissão de Constituição e Justiça. Desde então, não se deu prosseguimento ao seu

\footnotetext{
${ }^{5}$ Disponível em: <http://www.conima.org.br/inst_filia>. Acesso em: 30 nov. 2015.

${ }^{6}$ Disponível o inteiro teor do projeto no Diário Oficial n ${ }^{\circ} 199$ da Câmara dos Deputados, de 3 de dezembro de 1998: <http://imagem.camara.gov.br/Imagem/d/pdf/DCD03DEZ1998.pdf\#page=71> acesso em 18 de maio 2017.
} 
andamento, restando arquivado, o que, naquela ocasião, frustrou a expectativa de um marco legal para a mediação no Brasil (PINHO; CABRAL, 2016, p. 5).

Mesmo enfrentando a carência de uma regulamentação própria, o país seguiu a tendência internacional de incorporação no seio social de uma mentalidade jurídica voltada para os meios alternativos de solução de conflitos, o que pode inclusive ser comprovado através da Pesquisa Nacional por Amostra de Domicílios - PNAD ${ }^{7}$. Realizada pelo Instituto Brasileiro de Geografia e Estatística - IBGE, no ano de 2009, em parceria com o Conselho Nacional de Justiça - CNJ, investigou, em caráter suplementar, o aspecto da Vitimização e Justiça. Essa investigação constituiu uma atualização importante dos referenciais em nível nacional, visto que o diagnóstico anterior sobre o tema datava de 1988, ou seja, mais de 20 anos de defasagem.

O ponto de destaque da PNAD desenvolvida pelo IBGE no que concerne à mediação e grande de interesse para este trabalho, foi verificar a forma como a população brasileira vinha vivenciando os conflitos e como tentava resolvê-los. Buscou-se averiguar os tipos de disputas costumeiramente vivenciadas e a maneira com que as pessoas procuravam dirimi-las, seja pelo acionamento do Poder Judiciário seja através do instâncias alternativas, ou ainda pela adoção outras vias.

Conforme Gráfico 31 trazido no relatório, mediação e conciliação disparam como primeira alternativa das pessoas maiores de 18 anos que deixaram de procurar o Poder Judiciário para solucionar seus problemas, totalizando um percentual de $27,6 \%$ dos entrevistados. Dentre os principais motivos relatados pelos participantes estão a demora excessiva dos processos judiciais $(15,9 \%)$, o desconhecimento quanto à possibilidade de ingressar com uma demanda judicial $(6,8 \%)$, a descrença na justiça $(6,6 \%)$, o elevado custo do processo $(6 \%)$ e por fim, mas que ainda chama atenção, o fato das instâncias judiciais se localizarem em áreas distantes da população, sobretudo no interior do país $(1,4 \%)$.

Em termos regionais ${ }^{8}$, as regiões Sudeste e Nordeste se posicionaram bem a frente no que tange ao número de pessoas, em valores absolutos, que preferiram a via não adversarial. Aproximadamente $30 \%$ dos entrevistados residentes nessas localidades optaram por essa alternativa, percentual este que também se aproxima dos encontrados no centro-oeste, norte e sul do Brasil.

O interesse do Poder Judiciário em estimular o desenvolvimento dos meios alternativos de solução de conflitos ganhou contornos mais evidentes com a edição da Resolução $n^{0} 125$ de 2010 pelo Conselho Nacional de Justiça, órgão responsável pela estruturação da política judiciária nacional. Este diploma normativo trouxe novas diretrizes ao desenvolvimento da mediação no país e teve um papel fundamental no seu fortalecimento.

O professor e colaborador do novo Código de Processo Civil, Fredie Didier Junior (2015, pp. 174-175), ressalta sobre esta resolução 125 que a consideranda cumpre bem a sua função didática, revelando com clareza a sua importância e os objetivos que visa cumprir ${ }^{9}$. E

\footnotetext{
${ }^{7}$ Para consulta na íntegra, acessar: <http://biblioteca.ibge.gov.br/visualizacao/livros/liv47311.pdf>. Acesso em: 11 de maio de 2017.

${ }^{8}$ Para maior detalhamento quanto a este ponto, verificar a tabela 1.3.5. do Relatório sobre Vitimização e Acesso à Justiça no Brasil disponível em < http://biblioteca.ibge.gov.br/visualizacao/livros/liv47311.pdf> acesso em 18 de mai. 2017.

${ }^{9} \mathrm{Na}$ visão do professor , "CONSIDERANDO que compete ao Conselho Nacional de Justiça o controle da atuação administrativa e financeira do Poder Judiciário, bem como zelar pela observância do art. 37 da Constituição da República; CONSIDERANDO que a eficiência operacional, o acesso ao sistema de Justiça e a responsabilidade social são objetivos estratégicos do Poder Judiciário, nos termos da Resolução CNJ n ${ }^{\circ} 70$, de 18 de março de 2009; CONSIDERANDO que o direito de acesso à Justiça, previsto no art. $5^{\circ}$, XXXV, da Constituição Federal além de vertente formal perante os órgãos judiciários, implica acesso à ordem jurídica justa; CONSIDERANDO que, por isso, cabe ao Judiciário estabelecer política pública de tratamento adequado
} 
ainda no que tange ao dito diploma, Pinho e Cabral (ob. cit., pp. 6-7), discorre sobre as seguintes premissas:

[...] a) o direito de acesso à Justiça, previsto no art. $5^{\circ}, \mathrm{XXXV}$, da Constituição Federal, além da vertente formal perante os órgãos judiciários, implica acesso à ordem jurídica justa;b) nesse passo, cabe ao Judiciário estabelecer política pública de tratamento adequado dos problemas jurídicos e dos conflitos de interesses, que ocorrem em larga e crescente escala na sociedade, de forma a organizar, em âmbito nacional, não somente os serviços prestados nos processos judiciais, como também os que possam sê-lo mediante outros mecanismos de solução de conflitos, em especial dos consensuais, como a mediação e a conciliação; c) a necessidade de se consolidar uma política pública permanente de incentivo e aperfeiçoamento dos mecanismos consensuais de solução de litígios; d) a conciliação e a mediação são instrumentos efetivos de pacificação social, solução e prevenção de litígios, e que a sua apropriada disciplina em programas já implementados no país tem reduzido a excessiva judicialização dos conflitos de interesses, a quantidade de recursos e de execução de sentenças; e) é imprescindível estimular, apoiar e difundir a sistematização e o aprimoramento das práticas já adotadas pelos tribunais; f) a relevância e a necessidade de organizar e uniformizar os serviços de conciliação, mediação e outros métodos consensuais de solução de conflitos, para lhes evitar disparidades de orientação e práticas, bem como para assegurar a boa execução da política pública, respeitadas as especificidades de cada segmento da Justiça.

Uma das importantes previsões da resolução ${ }^{10}$ foi, sem dúvida, a determinação da criação pelos Tribunais dos estados de Núcleos Permanentes de Métodos Consensuais de

dos problemas jurídicos e dos conflitos de interesses, que ocorrem em larga e crescente escala na sociedade, de forma a organizar, em âmbito nacional, não somente os serviços prestados nos processos judiciais, como também os que possam sê-lo mediante outros Conselho Nacional de Justiça mecanismos de solução de conflitos, em especial dos consensuais, como a mediação e a conciliação; CONSIDERANDO a necessidade de se consolidar uma política pública permanente de incentivo e aperfeiçoamento dos mecanismos consensuais de solução de litígios; CONSIDERANDO que a conciliação e a mediação são instrumentos efetivos de pacificação social, solução e prevenção de litígios, e que a sua apropriada disciplina em programas já implementados nos país tem reduzido a excessiva judicialização dos conflitos de interesses, a quantidade de recursos e de execução de sentenças; CONSIDERANDO ser imprescindível estimular, apoiar e difundir a sistematização e o aprimoramento das práticas já adotadas pelos tribunais; CONSIDERANDO a relevância e a necessidade de organizar e uniformizar os serviços de conciliação, mediação e outros métodos consensuais de solução de conflitos, para lhes evitar disparidades de orientação e práticas, bem como para assegurar a boa execução da política pública, respeitadas as especificidades de cada segmento da Justiça; CONSIDERANDO que a organização dos serviços de conciliação, mediação e outros métodos consensuais de solução de conflitos deve servir de princípio e base para a criação de Juízos de resolução alternativa de conflitos, verdadeiros órgãos judiciais especializados na matéria; CONSIDERANDO o deliberado pelo Plenário do Conselho Nacional de Justiça na sua $117^{\text {a }}$ Sessão Ordinária, realizada em de 23 de 2010, nos autos do procedimento do Ato 000605982.2010.2.00.0000".

${ }^{10} \mathrm{O}$ artigo $7^{\circ}$ da Resolução 125 de 2010, que passou por recente alteração, assim dispõe:

Art. 7o Os tribunais deverão criar, no prazo de 30 dias, Núcleos Permanentes de Métodos Consensuais de Solução de Conflitos (Núcleos), coordenados por magistrados e compostos por magistrados da ativa ou aposentados e servidores, preferencialmente atuantes na área, com as seguintes atribuições, entre outras: (Redação dada pela Emenda no 2, de 08.03.16) 
Solução de Conflitos. Essa disposição foi alterada em 2013, quando passou a constar a obrigatoriedade de instalação dos Centros Judiciários de Solução de Conflitos e Cidadania (CEJUSC) em locais com até quatro Juízos, Juizados ou Varas cíveis, fazendárias, previdenciárias ou de família. No entanto, apesar dessa previsão, a criação dos CEJUSC não foi incorporada por todos os tribunais (COELHO, ob. cit., p. 108).

O amplo impulso dado pelo próprio Poder Judiciário à formas de solução pacífica de conflitos não se limitou à edição da resolução supra referida. A partir de discussões travadas desde 2009, quando foi convocada uma Comissão de Juristas, presidida pelo Ministro Luiz Fux, houve a criação de um novo Código de Processo Civil em vigor desde 2016. Os debates traziam sempre uma grande preocupação dos membros responsáveis por sua elaboração com os meios alternativos de solução de controvérsias, com ênfase para a conciliação e a mediação (PINHO; CABRAL, ob. cit., p. 8).

Após essas tratativas que antecederam a promulgação do Projeto do novo Código de Processo Civil em 2011, foi proposto o Projeto de Lei $\mathrm{n}^{\circ}$ 517, no mesmo ano, que tinha como objetivo a regulamentação da mediação judicial e extrajudicial, de modo a criar um sistema afinado tanto com o futuro CPC, bem como com a Resolução $n^{\circ} 125$ do CNJ (Idem, p. 11).

I - desenvolver a Política Judiciária de tratamento adequado dos conflitos de interesses, estabelecida nesta Resolução;

II - planejar, implementar, manter e aperfeiçoar as ações voltadas ao cumprimento da política e suas metas;

III - atuar na interlocução com outros Tribunais e com os órgãos integrantes da rede mencionada nos arts. 5o e 6o;

IV - instalar Centros Judiciários de Solução de Conflitos e Cidadania que concentrarão a realização das sessões de conciliação e mediação que estejam a cargo de conciliadores e mediadores, dos órgãos por eles abrangidos;

$\mathrm{V}$ - incentivar ou promover capacitação, treinamento e atualização permanente de magistrados, servidores, conciliadores e mediadores nos métodos consensuais de solução de conflitos;

VI - propor ao Tribunal a realização de convênios e parcerias com entes públicos e privados para atender aos fins desta Resolução;

VII - criar e manter cadastro de mediadores e conciliadores, de forma a regulamentar o processo de inscrição e de desligamento; (Incluído pela Emenda no 2, de 08.03.16)

VIII - regulamentar, se for o caso, a remuneração de conciliadores e mediadores, nos termos do art. 169 do Novo Código de Processo Civil combinado com o art. 13 da Lei de Mediação. (Incluído pela Emenda no 2, de 08.03.16)

§ 1o A criação dos Núcleos e sua composição deverão ser informadas ao Conselho Nacional de Justiça.

§ 2o Os Núcleos poderão estimular programas de mediação comunitária, desde que esses centros comunitários não se confundam com os Centros de conciliação e mediação judicial, previstos no Capítulo III, Seção II.

§ 3o Na hipótese de conciliadores, mediadores e Câmaras Privadas de Conciliação e Mediação credenciadas perante o Poder Judiciário, os tribunais deverão criar e manter cadastro ou aderir ao Cadastro Nacional de Mediadores Judiciais e Conciliadores, de forma a regulamentar o processo de inscrição e de desligamento desses facilitadores. (Redação dada pela Emenda no 2, de 08.03.16)

$\S 4$ o Os tribunais poderão, nos termos do art. 167, § 6o, do Novo Código de Processo Civil, excepcionalmente e desde que inexistente quadro suficiente de conciliadores e mediadores judiciais atuando como auxiliares da justiça, optar por formar quadro de conciliadores e mediadores admitidos mediante concurso público de provas e títulos. (Redação dada pela Emenda no 2, de 08.03.16)

$\S 5$ o Nos termos do art. 169, $\S 1^{\circ}$, do Novo Código de Processo Civil, a Mediação e a Conciliação poderão ser realizadas como trabalho voluntário. (Incluído pela Emenda no 2, de 08.03.16)

$\S 60$ Aos mediadores e conciliadores, inclusive membros das Câmaras Privadas de Conciliação, aplicam-se as regras de impedimento e suspeição, nos termos do disposto no art. 134, IV, do Código de Processo Civil de 1973; no art. 148, II, do Código de Processo Civil de 2015 e na Resolução CNJ 200/2015. (Incluído pela Emenda no 2 , de 08.03 .16 )

$\S 7$ o Nos termos do art. 172 do Código de Processo Civil de 2015, o conciliador e o mediador ficam impedidos, pelo prazo de 1 (um) ano, contado do término da última audiência em que atuaram, de assessorar, representar ou patrocinar qualquer das partes. (Incluído pela Emenda no 2, de 08.03.16) 
Em seguida, no ano de 2013, , mais duas iniciativas legislativas surgiram e foram apensadas ao PLS $n^{\circ}$ 517. A primeira, a PLS n ${ }^{\circ} 405$ de 2013, decorrente do trabalho realizado por Comissão instituída pelo Senado e presidida pelo Ministro do Superior Tribunal de Justiça Luís Felipe Salomão; e a segunda, a PLS n ${ }^{\circ}$ 413/2013, fruto da Comissão instituída pelo Conselho Nacional de Justiça em parceria com o Ministério da Justiça, presidida pela Ministra Nancy Andrighi, também da Corte Superior, pelo Ministro Marco Buzzi, e pelo Secretário da Reforma do Judiciário do Ministério da Justiça, Flávio Crocce Caetano (Idem, p. 12).

Esses três projetos foram discutidos e analisados em audiências públicas, sendo apresentado um substitutivo que visava congregá-los de forma harmônica, tendo sido aprovado pela Comissão de Constituição e Justiça e Cidadania do Senado em fevereiro de 2014, seguindo para a Comissão de Constituição e Justiça e Cidadania da Câmara, e sendo aprovado finalmente no Senado em 02 de junho de 2015.

Assim, em 16 de março de 2015, foi publicado então o novo Código de Processo Civil Brasileiro, a Lei 13.105 , que nos seus artigos 165 e seguintes ${ }^{11}$, regulamenta as

\section{${ }^{11}$ Seção V: Dos Conciliadores e Mediadores Judiciais}

Art. 165. Os tribunais criarão centros judiciários de solução consensual de conflitos, responsáveis pela realização de sessões e audiências de conciliação e mediação e pelo desenvolvimento de programas destinados a auxiliar, orientar e estimular a autocomposição.

$\S 1^{0} \mathrm{~A}$ composição e a organização dos centros serão definidas pelo respectivo tribunal, observadas as normas do Conselho Nacional de Justiça.

$\S 2^{\circ} \mathrm{O}$ conciliador, que atuará preferencialmente nos casos em que não houver vínculo anterior entre as partes, poderá sugerir soluções para o litígio, sendo vedada a utilização de qualquer tipo de constrangimento ou intimidação para que as partes conciliem.

$\S 3^{\circ} \mathrm{O}$ mediador, que atuará preferencialmente nos casos em que houver vínculo anterior entre as partes, auxiliará aos interessados a compreender as questões e os interesses em conflito, de modo que eles possam, pelo restabelecimento da comunicação, identificar, por si próprios, soluções consensuais que gerem benefícios mútuos.

Art. 166. A conciliação e a mediação são informadas pelos princípios da independência, da imparcialidade, da autonomia da vontade, da confidencialidade, da oralidade, da informalidade e da decisão informada.

$\S 1^{\circ}$ A confidencialidade estende-se a todas as informações produzidas no curso do procedimento, cujo teor não poderá ser utilizado para fim diverso daquele previsto por expressa deliberação das partes.

$\S 2^{\mathrm{o}} \mathrm{Em}$ razão do dever de sigilo, inerente às suas funções, o conciliador e o mediador, assim como os membros de suas equipes, não poderão divulgar ou depor acerca de fatos ou elementos oriundos da conciliação ou da mediação.

$\S 3^{\circ}$ Admite-se a aplicação de técnicas negociais, com o objetivo de proporcionar ambiente favorável à autocomposição.

$\S 4^{\underline{0}}$ A mediação e a conciliação serão regidas conforme a livre autonomia dos interessados, inclusive no que diz respeito à definição das regras procedimentais.

Art. 167. Os conciliadores, os mediadores e as câmaras privadas de conciliação e mediação serão inscritos em cadastro nacional e em cadastro de tribunal de justiça ou de tribunal regional federal, que manterá registro de profissionais habilitados, com indicação de sua área profissional.

$\S 1^{\circ}$ Preenchendo o requisito da capacitação mínima, por meio de curso realizado por entidade credenciada, conforme parâmetro curricular definido pelo Conselho Nacional de Justiça em conjunto com o Ministério da Justiça, o conciliador ou o mediador, com o respectivo certificado, poderá requerer sua inscrição no cadastro nacional e no cadastro de tribunal de justiça ou de tribunal regional federal.

$\S 2$ E Efetivado o registro, que poderá ser precedido de concurso público, o tribunal remeterá ao diretor do foro da comarca, seção ou subseção judiciária onde atuará o conciliador ou o mediador os dados necessários para que seu nome passe a constar da respectiva lista, a ser observada na distribuição alternada e aleatória, respeitado o princípio da igualdade dentro da mesma área de atuação profissional.

$\S 3^{o}$ Do credenciamento das câmaras e do cadastro de conciliadores e mediadores constarão todos os dados relevantes para a sua atuação, tais como o número de processos de que participou, o sucesso ou insucesso da atividade, a matéria sobre a qual versou a controvérsia, bem como outros dados que o tribunal julgar relevantes. 
diretrizes e o procedimento de mediação judicial; e, em 29 de junho de 2015, a Lei n. 13.140, que dispõe sobre a mediação entre particulares como meio de solução de controvérsias e sobre a autocomposição de conflitos no âmbito da Administração Pública.

$\S 4^{\circ}$ Os dados colhidos na forma do $\S 3^{\circ}$ serão classificados sistematicamente pelo tribunal, que os publicará, ao menos anualmente, para conhecimento da população e para fins estatísticos e de avaliação da conciliação, da mediação, das câmaras privadas de conciliação e de mediação, dos conciliadores e dos mediadores.

$\S 5^{\circ}$ Os conciliadores e mediadores judiciais cadastrados na forma do caput, se advogados, estarão impedidos de exercer a advocacia nos juízos em que desempenhem suas funções.

$\S 6^{0} \mathrm{O}$ tribunal poderá optar pela criação de quadro próprio de conciliadores e mediadores, a ser preenchido por concurso público de provas e títulos, observadas as disposições deste Capítulo.

Art. 168. As partes podem escolher, de comum acordo, o conciliador, o mediador ou a câmara privada de conciliação e de mediação.

$\S 1^{\circ} \mathrm{O}$ conciliador ou mediador escolhido pelas partes poderá ou não estar cadastrado no tribunal.

$\S 2^{\mathrm{o}}$ Inexistindo acordo quanto à escolha do mediador ou conciliador, haverá distribuição entre aqueles cadastrados no registro do tribunal, observada a respectiva formação.

$\S 3^{\circ}$ Sempre que recomendável, haverá a designação de mais de um mediador ou conciliador.

Art. 169. Ressalvada a hipótese do art. $167, \S 6^{\circ}$, o conciliador e o mediador receberão pelo seu trabalho remuneração prevista em tabela fixada pelo tribunal, conforme parâmetros estabelecidos pelo Conselho Nacional de Justiça.

$\S 1^{\circ}$ A mediação e a conciliação podem ser realizadas como trabalho voluntário, observada a legislação pertinente e a regulamentação do tribunal.

$\S 2^{\underline{0}}$ Os tribunais determinarão o percentual de audiências não remuneradas que deverão ser suportadas pelas câmaras privadas de conciliação e mediação, com o fim de atender aos processos em que deferida gratuidade da justiça, como contrapartida de seu credenciamento.

Art. 170. No caso de impedimento, o conciliador ou mediador o comunicará imediatamente, de preferência por meio eletrônico, e devolverá os autos ao juiz do processo ou ao coordenador do centro judiciário de solução de conflitos, devendo este realizar nova distribuição.

Parágrafo único. Se a causa de impedimento for apurada quando já iniciado o procedimento, a atividade será interrompida, lavrando-se ata com relatório do ocorrido e solicitação de distribuição para novo conciliador ou mediador.

Art. 171. No caso de impossibilidade temporária do exercício da função, o conciliador ou mediador informará o fato ao centro, preferencialmente por meio eletrônico, para que, durante o período em que perdurar a impossibilidade, não haja novas distribuições

Art. 172. O conciliador e o mediador ficam impedidos, pelo prazo de 1 (um) ano, contado do término da última audiência em que atuaram, de assessorar, representar ou patrocinar qualquer das partes.

Art. 173. Será excluído do cadastro de conciliadores e mediadores aquele que:

I - agir com dolo ou culpa na condução da conciliação ou da mediação sob sua responsabilidade ou violar qualquer dos deveres decorrentes do art. $166, \S \S 1^{\circ}$ e $2^{\circ}$;

II - atuar em procedimento de mediação ou conciliação, apesar de impedido ou suspeito.

$\S 1^{\circ}$ Os casos previstos neste artigo serão apurados em processo administrativo.

$\S 2^{0} \mathrm{O}$ juiz do processo ou o juiz coordenador do centro de conciliação e mediação, se houver, verificando atuação inadequada do mediador ou conciliador, poderá afastá-lo de suas atividades por até 180 (cento e oitenta) dias, por decisão fundamentada, informando o fato imediatamente ao tribunal para instauração do respectivo processo administrativo.

Art. 174. A União, os Estados, o Distrito Federal e os Municípios criarão câmaras de mediação e conciliação, com atribuições relacionadas à solução consensual de conflitos no âmbito administrativo, tais como:

I - dirimir conflitos envolvendo órgãos e entidades da administração pública;

II - avaliar a admissibilidade dos pedidos de resolução de conflitos, por meio de conciliação, no âmbito da administração pública;

III - promover, quando couber, a celebração de termo de ajustamento de conduta.

Art. 175. As disposições desta Seção não excluem outras formas de conciliação e mediação extrajudiciais vinculadas a órgãos institucionais ou realizadas por intermédio de profissionais independentes, que poderão ser regulamentadas por lei específica.

Parágrafo único. Os dispositivos desta Seção aplicam-se, no que couber, às câmaras privadas de conciliação e mediação. 
Não obstante o surgimento desses marcos regulatórios tenha propiciado um ambiente favorável à propagação de sua utilização, não pode ser considerado como o fator exclusivo de sua institucionalização no Brasil. Outros fatores que não circunscritos a lei também devem ser observados para uma incorporação eficaz da mediação na cultura social. É o que passamos a examinar.

\section{Propostas para ampliação do uso Mediação no Brasil}

As perspectivas da mediação no Brasil são promissoras, mas dependem de vontade política para sua plena institucionalização na sociedade. É de grande relevo aferir quais as outras iniciativas fora do campo legislativo que poderiam contribuir de maneira efetiva para implementá-la.

Como ressalta Eleonora Coelho (ob. cit., p.111), para a transformação da chamada "cultura do litígio" em uma cultura pacificadora, com o objetivo de promoção e incentivo ao uso de métodos pacíficos, devem ser observados alguns fatores essenciais. O primeiro deles é indiscutivelmente a criação desse arcabouço legal eficaz - segundo o direito positivo, que parte da atuação do legislativo; e o segundo, está relacionado à renovação do ensino jurídico, da educação em geral e da promoção de políticas públicas - institucionalização pela incorporação ao comportamento social, o que leva em consideração tanto a atuação do Executivo quanto do Judiciário, que aqui deixaria de lado seu papel de protagonista.

Em relação à criação de uma referência normativa muito foi feito. Inúmeras propostas legislativas que visavam dar corpo à mediação e à conciliação surgiram nas últimas décadas, inclusive com a consolidação de dois marcos legais capazes de regulamentá-los de forma abrangente e completa: o novo Código de Processo Civil Brasileiro, a Lei 13.105 e a Lei 13.140, a Lei de Mediação brasileira, que traz os novos parâmetros de aplicação do instituto no Brasil.

Michelle Paumgartten (2016, p. 232) afirma que

inscrita no contexto judicial, a mediação se torna predestinada a cumprir o ritual de padrões processuais, que instrumentalizam e compatibilizam o dogma da efetividade da atividade jurisdicional, além do dever de funcionar direcionada à justiça (jurisdição estatal). Jacques Faget observa que esta dinâmica conduz a mediação a dois modos de existência paralela: (i) uma acepção não oficial que the confere uma concepção mais prescritiva do que normativa, na maioria das vezes criticada, pois gera um sentimento de insegurança por estar supostamente sujeita a equívocos, devido a ausência de regulamentos e da supervisão de um juiz (Estado); (ii) por detrás desta ideia, à sombra de uma existência oficial, a mediação é deslocada para outra realidade que lhe confere uma posição de legitimidade, garantindo-lhe maior aceitabilidade.

Flavia Pereira Hill, Gabriela Asmar, Vitor Lopes e Vivian Gama (2016, p. 167), ao comentarem a nova lei, apesar de considerarem o saldo positivo da trajetória da mediação, elencam cinco pontos que requerem maior atenção:

(i) maior clareza acerca da complementariedade entre mediação extrajudicial e Poder Judiciário; (ii) exequibilidade da cláusula compromissória; (iii) incentivos mais claros à mediação em conflitos 
de natureza comercial e societária; (iv) falta de clareza acerca dos requisitos para se exercer a função de mediador extrajudicial; e como uma das consequências do ponto (iv), (v) equilíbrio de oferta e demanda de serviços de mediação/estímulos ao aprimoramento da qualidade dos mediadores profissionais.

Alguns doutrinadores se colocam num tom mais crítico. Convidada para participar do seminário Como a mediação e a arbitragem podem ajudar no acesso e na agilização da Justiça, evento de iniciativa do Centro de Estudos Judiciários em parceria com o STJ, a jurista Ada Pellegrini Grinover, em entrevista, posiciona-se fortemente contrária à lei, pois esta representaria um retrocesso em relação ao pensamento dos especialistas na matéria e uma contradição com o que a Câmara dos Deputados já aprovou sobre o assunto por intermédio do Projeto de Lei do Código de Processo Civil $(C P C)^{12}$.

Entretanto, quanto ao segundo aspecto, ligado mais ao plano cultural, poucos avanços podem ser apontados. A sociedade brasileira ainda está pouco familiarizada com a matéria e não está habituada a utilizar esses métodos, tendo em vista que a judicialização é a forma consolidada de atuação de grande parte dos profissionais do Direito. De fato, essas vias consensuais não são práticas historicamente presentes em nossa cultura, tanto que os resultados das normas anteriores que previram a conciliação, como por exemplo a Lei que tratou dos Juizados Especiais Cíveis - Lei 9.099, não lograram o êxito esperado (PINHO; CABRAL; ob. cit., p. 287).

A exaustiva regulamentação conferida concomitantemente pelo NCPC e pela Lei de Mediação, ainda que tenha proporcionado alguns progressos, não foi contemplada por qualquer tipo de planejamento e/ou acompanhamento de sua concretização ${ }^{13}$. Daí a importância em se estabelecerem políticas públicas direcionadas à educação-aprendizagem e à transformação cultural voltada para a pacificação através da divulgação a respeito das formas consensuais de solução de conflitos. Dentro dessa perspectiva educacional, o ensino deve ser priorizado. É necessária a sua completa renovação, principalmente no campo jurídico, inserindo matérias relacionadas a este ponto do processo civil nas grades curriculares e nos estágios supervisionados.

Relembra Eleonora Coelho (ob. cit, p. 115) que a extrema litigiosidade encontrada hoje no foro nasce nas cadeiras das faculdades de Direito. Desde o primeiro ano, ao estudante é apresentado somente ao sistema adversarial judicial, como se este fosse o único remédio para todos os males. Não se estuda e não se incentiva a criação de uma cultura de paz. Selma Lemes (2015) considera que

as academias ainda perfilham grades curriculares utilizadas na formação do bacharel de 50 anos atrás, que não se coadunam com as necessidades atuais. Urge mudança estrutural que preserve a herança

\footnotetext{
${ }^{12}$ Disponível em: http://www.cjf.jus.br/cjf/noticias-do-cjf/2014/novembro/ada-pellegrini-fala-sobre-mediacao-eos-aspectos-gerais-do-marco-legal-em-seminario-no-cjf. Acesso em: 06 dez. 2015. Em palestra, a professora Ada Pellegrini Grinover reforça o posicionamento e afirma "a tardia ressurreição das nossas práticas conciliativas está ameaçada. O marco regulatório da mediação judicial não é esse projeto de lei”. A palestra foi proferida pela professora Ada Pellegrini Grinover no seminário "Como a mediação e a arbitragem podem ajudar no acesso e na agilização da Justiça", em 21 de novembro de 2014, na sede do Conselho da Justiça Federal em Brasília. Disponível em: http://www.cjf.jus.br/noticias-do-cjf/2014/novembro/especialistas-em-mediacaojudicial-criticam-projeto-que-tramita-no-congresso. Acesso em: 06 dez. 2015.

${ }^{13}$ Segundo Flavia Hill, Gabriela Assmar, Vitor Lopes e Vivian Gama (2016. p. 189), a aplicação equivocada da mediação terá o efeito inverso de concretizar a inicial desconfiança das partes com o novo método. O que antes era desconfiança por ser desconhecido, poderá se tornar rejeição, em decorrência de uma experiência prática desastrosa, devido à aplicação deturpada do método
} 
jurídica existente, mas adaptada aos novos tempos. É justamente na academia jurídica que devem encontrar paragens o diálogo da renovação e da mudança de paradigmas, da ciência conformadora para a ciência transformadora, apregoadas pelo sociólogo português Boaventura de Souza Santos.

Algumas universidades já possuem matérias que se ocupam dos meios alternativos de solução de conflitos todavia, em sua grande maioria, não as integram como parte obrigatória do currículo, mas tão somente como disciplinas eletivas. ${ }^{14}$ Outro fator que se considera importante é a incorporação desse tópico nos exames de Ordem dos Advogados do Brasil $^{15}$ e nas provas de concursos públicos na área jurídica, implicando na sua inserção na formação dos Magistrados, Defensores, membros do Ministério Público e outros profissionais do Direito.

Na seara das Políticas Públicas, destaca-se a iniciativa de Tribunais de Justiça dos estados que fomentam centros de mediação comunitária pelo país. No Rio de Janeiro ${ }^{16}$, por exemplo, o TJRJ realizou um curso de capacitação de profissionais de diversas áreas para atuarem como mediadores comunitários em núcleos montados pela Prefeitura e em paróquias ligadas à Arquidiocese metropolitana do Rio. Esses espaços têm como principal meta estimular uma renovação das relações sociais dos indivíduos que procuram pelo procedimento da mediação extrajudicial em uma perspectiva de prevenção ao litígio e ao agravamento do confronto.

Um aspecto que precisa ser enfatizado é o de que esses centros comunitários levam a gratuidade do acesso à justiça à concretude. Além de oferecerem o serviço de mediação, que abre aos envolvidos a possibilidade de reabrirem as conversas e pacificarem a questão com um acordo extrajudicial, ainda disponibiliza à população orientação e uma rede de contatos em órgãos e entidades públicos e privados. Com isso, aproximam-se essas serventias ${ }^{17} \mathrm{de}$ apoio ao cidadão daquele que as procuram de forma rápida e precisa. No entanto, cabe ressalvar que esse tipo de projeto é incipiente no país ${ }^{18}$ e atinge uma parcela ainda pouco

\footnotetext{
14 “Muitas faculdades de direito já incluem as ADR em suas grades curriculares, seja como disciplina obrigatória [como, por exemplo, a Fundação Getúlio Vargas - FGV; a Universidade Federal de Pernambuco - UFPE, entre outras; sendo que a Fundação Armando Álvares Penteado - FAAP já anunciou publicamente sua intenção de também tornar a disciplina obrigatória (que atualmente é facultativa)], seja como disciplina facultativa (como, por exemplo, a Universidade Federal de Santa Catarina - UFSC). Também é de se destacar a posição da Universidade de São Paulo - USP, que tem cursos na área há muitos anos. A Pontifícia Universidade Católica de São Paulo, em sua conhecida posição de vanguarda acadêmica, também já vem ofertando a matéria como disciplina facultativa na grade curricular do curso de graduação em Direito, tendo sido, inclusive, elogiada por isso. Contudo, é tempo de avançar, inserindo-se a matéria como disciplina obrigatória na grade curricular dos cursos de graduação em Direito". (CAHALI; RODOVALHO, 2013)

15 Disponível em: <http://www.oab.org.br/noticia/25169/oab-estudara-insercao-da-mediacao-conciliacao-earbitragem-no-exame>. Acesso em: 06 dez. 2015.

${ }^{16}$ No ano de 2016 foram inaugurados dois centros com a Prefeitura, um no Catumbi, denominado de Paulo César Salomão e outro na Rocinha, que recebeu o nome de Salim Salomão. Na parte relacionada à Igreja, foram abertos em sete paróquias ${ }^{16}$, em seis dos oito Vicariatos que compõe a arquidiocese.

${ }^{17}$ Por exemplo, uma situação de violência feminina conta com um amplo leque de serviços e órgãos que a mulher pode procurar. Mas não é raro ficar desorientada sem saber aonde se dirigir primeiro.

18 O Estado de Minas Gerais tem uma experiência de sucesso a ser compartilhada: criou o Programa de Mediação de Conflito que tem por objetivo empreender ações de articulação comunitária para prevenir conflitos potenciais e/ou concretos, evitando ações violentas e delituosas. O programa configura-se como fonte de atuação integrada no sistema judiciário, representando nova orientação na percepção, manejo e resolução de conflitos, com vistas à convivência social harmônica (RAMOS JÚNIOR, 2016, p. 522).
} 
expressiva da população. É preciso que se alastrem outros empreendimentos e parcerias nesse sentido.

\section{CONCLUSÃO}

Esta pesquisa analisou as principais etapas de institucionalização da mediação no Brasil. No campo legislativo, foram várias as iniciativas para compor de projetos de lei que regulamentassem este meio alternativo de solução de controvérsias com o fulcro de lhe conferir maior precisão e segurança jurídica aos que optarem pela sua utilização. Atualmente ainda que algumas especificidades sejam tratadas em leis especiais, dois são os diplomas normativos que regem esta matéria: o novo Código de Processo Civil Brasileiro, consolidado na Lei 13.105 de 2015 e a Lei 13.140 de 2015, também conhecida como a Lei de mediação brasileira.

Em que pese as inúmeras fontes legislativas que se propuseram a desenvolver essa temática, algumas vozes se levantaram para apontar que este cenário não corroborava necessariamente para um aumento do uso dessas formas consensuais. Era preciso que outras iniciativas fossem planejadas, acompanhadas e fomentadas pelo Poder Público. Atentou-se portanto, para a deficiência de informação acerca dos benefícios e vantagens do procedimento de mediação bem como para a carência de disciplinas específicas nos bancos de formação de profissionais do Direito e nos exames de preparação para exercício da profissão. O estudo deste ramo do direito processual civil ainda é incipiente no Brasil e na grande maioria das universidades do país é restrito à disciplinas eletivas, o que ainda limita o acesso a este conhecimento.

Dentre as políticas públicas que estão sendo fomentadas estão as concernentes à criação de centros judiciários de solução pacífica de controvérsias, os CEJUSCs, e a criação de centros comunitários a partir de iniciativa dos Tribunais de Justiça dos estados. Não obstante, ainda é longo o caminho que precisa se percorrido para uma popularização do uso de meios alternativos, sobretudo da mediação, para equacionamento das disputas e consequente mudança da cultura social do litígio para a pacificação. 


\section{REFERÊNCIAS}

BARBADO, Michelle Tonon. Reflexões sobre a institucionalização da Mediação no Direito Positivo Brasileiro. In: AZEVEDO, André Gomma de (Org.). Estudos em Arbitragem, Mediação e Negociação. Brasília: Grupos de Pesquisa, 2004. p. 206. Disponível em: <http://www.arcos.org.br/livros/estudos-de-arbitragem-mediacao-e-negociacao-vol3/parte-iidoutrina-parte-especial/reflexoes-sobre-a-institucionalizacao-da-mediacao-no-direitopositivo-brasileiro> . Acesso em: 30 nov. 2015.

BARBOSA, Oriana Piske de Azevedo; SILVA, Cristiano Alves da. Os métodos consensuais de solução de conflitos no âmbito do novo código de processo civil brasileiro (lei 13.105/15). Disponível em: <http://www.tjdft.jus.br/institucional/imprensa/noticias/arquivos/copy5_of_artigo.pdf> acesso em 16 de fev. 2017.

BARBOSA MOREIRA, José Carlos. O futuro da justiça: Alguns Mitos. Revista da Academia Brasileira de Letras Jurídicas. n. 17, p. 159. Disponível em:http://www.ablj.org.br/revistas/revista17/revista17\%20\%20JOS\%C3\%89\%20CARLOS\% 20BARBOSA\%20MOREIRA0001.pdf. Acesso em: 05 dez. 2015.

BRASIL. Constituição (1988) Constituição da República Federativa do Brasil. 50 ed. São Paulo: Saraiva, 2017.

Lei 13.140/2015, de 26 de junho de 2015. Dispõe sobre a mediação entre particulares como meio de solução de controvérsias e sobre a autocomposição de conflitos no âmbito da administração pública; altera a Lei $\mathrm{n}^{\circ} 9.469$, de 10 de julho de 1997 , e o Decreto $\mathrm{n}^{\circ}$ 70.235 , de 6 de março de 1972; e revoga o $\S 2^{\circ}$ do art. $6^{\circ}$ da Lei $n^{\circ} 9.469$, de 10 de julho de 1997. Brasília: 2015. Disponível em < http://www.planalto.gov.br/ccivil_03/_ato20152018/2015/Lei/L13140.htm> Acesso em 17 de fev. 2017.

. Lei 13.105/2015, de 16 de março de 2015. Código de Processo Civil. Brasília: 2015. Disponível em < http://www.planalto.gov.br/ccivil_03/_ato20152018/2015/lei/113105.htm> Acesso em 20 de jan. 2017.

CAPPELLETTI, Mauro. Os Métodos Alternativos de Solução de Conflitos no Quadro do Movimento Universal de Acesso à Justiça. Revista de Processo. São Paulo: Revista dos Tribunais, v.74, 1994.

CAHALI, Francisco José. RODOVALHO, Thiago. Mediação nos cursos de Direito estimulará mudança. Revista $O$ Consultor Jurídico. 12 dez. 2013. Disponível em: http://www.conjur.com.br/2013-dez-12/mediacao-cursos-direito-estimulara-mudanca-culturalitigio. Acesso em: 06 dez. 2015.

COELHO, Eleonora. Desenvolvimento da Cultura dos Métodos Adequados de Solução de Conflitos: Uma urgência para o Brasil. In ROCHA, Caio Cesar Vieira; SALOMÃO, Luis Felipe (Cords.). Arbitragem e Mediação - a reforma da Legislação Brasileira. São Paulo: Atlas, 2015.

CONIMA. Disponível em: http://www.conima.org.br/inst_filia. Acesso em: 30 nov. 2015. 
CPR. Disponível em: https://www.justice.gov.uk/courts/procedure-rules/civil/rules/part01. Acesso em: 05 nov. 2015.

DIDIER JR, Fredie. Curso de Direito Processual Civil: introdução ao direito processual civil, parte geral e processo de conhecimento. 17. ed. Salvador: JusPodivm, 2015.

FOLEY, Gláucia Falsarella; CAETANO, Flávio Crocce. Justiça para Todos. Disponível em: http://www.tjdft.jus.br/institucional/imprensa/artigos/2013/justica-para-todos-2013-juizaglaucia-falsarella-foley. Acesso em: 06 dez. 2015.

GABBAY, Daniela Monteiro. Mediação \& Judiciário no Brasil e nos Estados Unidos: condições, desafios e limites para a institucionalização da mediação no Judiciário. Brasília: Gazeta Jurídica, 2013.

GRINOVER, Ada Pellegrini. Os métodos consensuais de solução de conflitos no novo código de processo civil. Disponível em < http://estadodedireito.com.br/conflitosnonovo/> Acesso em 17 de fev. 2017.

HILL, Flavia Pereira; ASSMAR, Gabriela. et al. In: Marco Legal da Mediação no Brasil Comentários à Lei $\mathbf{n}^{\circ}$ 13.140, de 26 de junho de 2015. Cord. Durval Hale; Humberto Dalla Bernardina de Pinho e Trícia Navarro Xavier Cabral. São Paulo: Atlas, 2016. p. 167.

IBGE. Disponível em: http://biblioteca.ibge.gov.br/visualizacao/livros/liv47311.pdf. Acesso em: 11 de maio de 2017.

LEMES, Selma Ferreira. Os procedimentos arbitrais e as funções dos advogados. Disponível em: http://selmalemes.adv.br/artigos/artigo35.pdf. Acesso em: 06 dez. 2015.

NOBRE, Marcelo. A Mediação On-line. In: ROCHA, Caio Cesar Vieira; SALOMÃO, Luis Felipe (Cords.). Arbitragem e Mediação - a reforma da Legislação Brasileira. São Paulo: Atlas, 2015. p. 262.

OAB. Disponível em: http://www.oab.org.br/noticia/25169/oab-estudara-insercao-damediacao-conciliacao-e-arbitragem-no-exame. Acesso em: 06 dez. 2015.

PANTOJA, Fernanda Medina. ALMEIDA, Rafael Alves. Os métodos "alternativos" de solução de conflitos (ADRs). In: ALMEIDA, Diogo A. Rezende de; PANTOJA, Fernanda Medina. Áreas de atuação da mediação de conflitos. In: ALMEIDA, Tania; PELAJO, Samantha; JONATHAN, Eva. Mediação de conflitos para iniciantes, praticantes e docentes. Salvador: Ed. Juspodium, 2016, pp. 55-69.

PAUMGARTTEN, Michele. Disposições Finais. In: HALE, Durval; PINHO, Humberto Dalla Bernardina de; CABRAL, Trícia Navarro Xavier (Coords.) Marco legal da mediação no Brasil - Comentários à Lei $\mathbf{n}^{0} 13.140$ de 26 de junho de 2015. São Paulo: Atlas, 2016.

PINHO, Humberto Dalla Bernardina de; CABRAL, Trícia Navarro Xavier. Marco Legal da Mediação no Brasil - Comentários à Lei no 13.140 de 26 de junho de 2015. Coord. Durval Hale, Humberto Dalla Bernardina de Pinho e Trícia Navarro Xavier Cabral. São Paulo: Atlas, 2016. p. 6-7. 
RAMOS JÚNIOR, Ronan. Mediação comunitária: panorama sobre uma experiência em Minas Gerais. In: ALMEIDA, Tania; PELAJO, Samantha; JONATHAN, Eva. Mediação de conflitos para iniciantes, praticantes e docentes. Salvador: JusPodivm, 2016.

RODRIGUES JÚNIOR, Walsir Edson. A Prática da Mediação e o Acesso à Justiça. Belo Horizonte: Editora Del Rey, 2006. p. 161.

STUMPF, Juliano da Costa. Poder Judiciário: morosidade e inovação. Coleção Administração Judiciária, v. 2. Porto Alegre: Tribunal de Justiça do Estado do Rio Grande do Sul, Departamento de Artes Gráficas, 2009.

WEINGÄRTNER, Lis. Mediação é escolha alternativa para resolução de conflitos. Revista Justilex , ano VII, $n^{\circ} 76$, abr. 2009. 